\title{
Marital status is an independent prognostic factor for tracheal cancer patients: an analysis of the SEER database
}

\author{
Mu Li ${ }^{1}$, Chen-Yang Dai ${ }^{1}$, Yu-Ning Wang ${ }^{2}$, Tao Chen ${ }^{1}$, Long Wang ${ }^{1}$, Ping Yang ${ }^{3}$, Dong \\ $\mathrm{Xie}^{1}$, Rui Mao', Chang Chen ${ }^{1}$ \\ ${ }^{1}$ Department of Thoracic Surgery, Shanghai Pulmonary Hospital, Tongji University School of Medicine, Shanghai, People's \\ Republic of China \\ ${ }^{2}$ Deloitte and Touche Financial Advisory Services Limited, Shanghai, People's Republic of China \\ ${ }^{3}$ Division of Epidemiology, Department of Health Sciences Research, Mayo Clinic, Rochester, MN, USA \\ Correspondence to: Chang Chen, email: changchenc@hotmail.com \\ Keywords: tracheal cancer, marital status, socio-economics, SEER, survival analysis \\ Received: June 07, 2016 Accepted: October 12, $2016 \quad$ Published: October 21, 2016
}

\section{ABSTRACT}

Background: Although marital status is an independent prognostic factor in many cancers, its prognostic impact on tracheal cancer has not yet been determined. The goal of this study was to examine the relationship between marital status and survival in patients with tracheal cancer.

Results: Compared with unmarried patients (42.67\%), married patients (57.33\%) had better 5-year OS (25.64\% vs. 35.89\%, $p=0.009)$ and 5-year TCSS (44.58\% vs. 58.75\%, $p=0.004$ ). Results of multivariate analysis indicated that marital status is an independent prognostic factor, with married patients showing better OS (hazard ratio [HR] = 0.78, 95\% confidence interval [CI] 0.64-0.95, $p=0.015$ ) and TCSS (HR = 0.70, 95\% CI 0.54-0.91, $p=0.008$ ). In addition, subgroup analysis suggested that marital status plays a more important role in the TCSS of patients with non-low-grade malignant tumors ( $H R=0.71$, 95\% CI 0.53-0.93, $p=0.015$ ).

Methods: We extracted 600 cases from the Surveillance, Epidemiology, and End Results (SEER) database. Variables were compared by Pearson chi-squared test, $t$-test, log-rank test, and multivariate Cox regression analysis. Overall survival (OS) and tracheal cancer-specific survival (TCSS) were compared between subgroups with different pathologic features and tumor stages.

Conclusions: Marital status is an independent prognostic factor for survival in patients with tracheal cancer. For that reason, additional social support may be needed for unmarried patients, especially those with non-low-grade malignant tumors.

\section{INTRODUCTION}

Tracheal cancer is a rare disease with relatively poor outcomes $[1,2]$. This cancer accounts for less than $0.1 \%$ of all malignancies, and the 5 -year overall survival (OS) rate is only $27.1 \%[2,3]$. Because most previous studies on tracheal cancer were based on small samples [4-7], large sample studies are needed to improve our understanding of this complex disease. In addition, the concepts of health and disease have evolved greatly over the past decades, with a greater emphasis now placed on the role of social determinants in disease development $[8,9]$. However, former prognosis analysis mainly focused on pathological and clinical characteristics [10], with few studies addressing the impact of social determinants.
Marital status is an independent prognostic factor for survival in numerous cancers, and married patients have demonstrated better survival in lung cancer, prostate cancer, and breast cancer [11-13]. Marital status is an important type of social support and can greatly affect the patient's mood, quality of life, financial status, and coping strategies [14, 15]. However, our knowledge about its effect on prognosis in tracheal cancer is limited.

In this study, we used data from the Surveillance, Epidemiology, and End Results (SEER) program, which consists of 18 population-based cancer registries covering approximately $30 \%$ of the population in the United States. This database provides both clinical records and data on social determinants, including marital status and county level socio-economic data. In this study, we used SEER 
data to examine the effect of marital status and other prognostic factors on tracheal cancer.

\section{RESULTS}

\section{Demographic and clinical characteristics}

A total of 600 patients in the SEER database from 1990 to 2010 were included in this study. Demographic, clinicopathologic, and treatment data are shown in Table 1. Among the included patients, 344 were married (57.33\%), and 256 were unmarried $(42.67 \%)$, with mean ages of 63.65 \pm 12.98 and $63.60 \pm 12.98$ years, respectively $(p=0.963)$. Compared with unmarried patients, married patients were more likely to be male $(62.79 \%$ vs. $45.31 \%, p<0.001)$. Despite that the race ratio was different between the married and the unmarried group $(p=0.005)$, the proportion of white patients was highest in both groups $(79.65 \%$ vs. $78.13 \%$ ). The two groups did not differ significantly with regards to other baseline characteristics, including histologic type, disease extension, tumor grade, selection of surgery, and selection of radiotherapy $(p>0.05)$.

\section{Marital status and overall survival (OS)}

The OS curve generated using the Kaplan-Meier method shows a survival difference according to marital status (log-rank test $p=0.009)$ (Figure 1A). The median OS of married patients (21 months, 95\% confidence interval [CI] 14.67-27.33 months) was longer than that of unmarried patients (13 months, 95\% CI 9.70-16.30 months). Similarly, the 5-year OS rate for married patients $(35.89 \%)$ was higher than that of unmarried patients $(25.64 \%)$ (Table 2). Results of the log-rank test showed that age, race, histologic type, tumor grade, disease extension, and treatment (i.e., surgery or radiotherapy) were significantly associated with OS in these patients. After adjusting for these variables and other socioeconomic factors, marital status was found to be an independent prognostic factor, and married patients had better OS compared to unmarried patients (hazard ratio $[\mathrm{HR}]=0.78,95 \%$ CI $0.64-0.95, p=0.015$ ). No significant association between county-level socioeconomic status and OS was identified by univariate or multivariate analysis (Table 2).

\section{Marital status and tracheal cancer specific survival (TCSS)}

Median TCSS was also longer for married patients (98 months, 95\% CI 67.45-128.56 months) than for unmarried patients (38 months, 95\% CI 16.66-59.34 months, log-rank test $p=0.004$ ) (Figure 1B). The 5-year TCSS rates for married patients and unmarried patients were $58.75 \%$ and $44.58 \%$, respectively (Table 3 ). Univariate analysis showed that age, race, histologic type, tumor grade, disease extension, and surgery type were significantly associated with TCSS. In addition, patients living in counties with higher median household incomes had better TCSS (5-year TCSS rate $55.81 \%$ vs. $42.86 \%$, $\log$-rank test $p=0.023$ ). After adjusting for demographic, clinical, and socioeconomic factors, results of multivariate Cox regression analysis confirmed that marital status is an independent prognostic factor, with better TCSS among married patients ( $\mathrm{HR}=0.70,95 \%$ CI $0.54-0.91$, $p=0.008$ ). However, multivariate analysis did not support the relationship between county-level household socioeconomic status and TCSS (HR $=0.97,95 \% \mathrm{CI}$ $0.69-1.36, p=0.858)$.

\section{Subgroup analysis according to histologic type and tumor stage}

Prognosis of tracheal cancer varies according to histologic type, with low-grade malignant tumors (LGMTs) associated with better outcomes [16]. Therefore, we divided the patients into two subgroups according to histologic type: LGMT vs. non-low-grade malignant tumor (NLGMT). In the NLGMT group, the 5-year TCSS survival rate for married patients $(48.48 \%)$ was higher than that of unmarried patients $(31.90 \%$, log-rank test $p=0.001$ ) (Figure 2A, Supplementary Table S1). Results of multivariate analysis showed that marriage was an independent prognostic factor for TCSS in this subgroup (reference: unmarried patients, $\mathrm{HR}=0.70,95 \%$ CI $0.53-0.92, p=0.012)$. However, in the LGMT group, marital status was not associated with TCSS (log-rank test $p=0.876$, multivariate analysis 0.197) (Figure 2B, Supplementary Table S2). In contrast, no association was found between marital status and OS in either subgroup (Supplementary Tables S3 and S4). Stage-by-stage univariate and multivariate analysis showed that married status was an independent prognostic factor for TCSS in localized disease (reference: unmarried patients, $\mathrm{HR}=0.48$, $95 \%$ CI $0.25-0.91, p=0.023$ ) but not in regional disease or distant metastasis (Supplementary Tables S5 and S6).

\section{DISCUSSION}

In 1977, Engel challenged the traditional "biomedical model" of disease and introduced the "biopsychosocial medical model" [8], which still influences research, medical education, and clinical practice in the 21 st century [9]. This model emphasizes viewing the patient as a "whole person" with emotions, feelings, and social context rather than just a disease [17-19].

The importance of marital status and other socioeconomic factors in cancer prognosis have since been recognized. For example, Zhang et al. [20] studied 16,910 gastric cancer patients and found that marital status was an independent prognostic factor for both OS and cancerspecific survival. In a study of 129,207 patients, LaPar et al. 
Table 1: Baseline demographic and clinical characteristics of patients

\begin{tabular}{|c|c|c|c|c|}
\hline & Total & Married & Unmarried $^{\mathbf{b}}$ & $P$ value $^{\mathrm{c}}$ \\
\hline & $600(100)$ & 344 (57.33) & $256(42.67)$ & \\
\hline Sex & & & & $<0.001$ \\
\hline Male & $332(55.33)$ & $216(62.79)$ & $116(45.31)$ & \\
\hline Female & $268(44.67)$ & $128(37.21)$ & $140(54.69)$ & \\
\hline Age at diagnosis, $\mathrm{y} \pm \mathrm{SD}$ & $63.63 \pm 14.53$ & $63.65 \pm 12.98$ & $63.60 \pm 12.98$ & 0.963 \\
\hline Race & & & & 0.005 \\
\hline White & $474(79.00)$ & $274(79.65)$ & $200(78.13)$ & \\
\hline Black & $77(12.83)$ & $34(9.88)$ & $43(16.80)$ & \\
\hline Other & $49(8.17)$ & $36(10.47)$ & $14(5.08)$ & \\
\hline Disease Extension & & & & 0.211 \\
\hline Localized & $220(36.67)$ & $134(38.95)$ & $86(33.59)$ & \\
\hline Regional & $205(34.17)$ & $110(31.98)$ & $95(37.11)$ & \\
\hline Distant & $96(16.00)$ & $50(14.53)$ & $46(17.97)$ & \\
\hline Unknown & $79(13.17)$ & $50(14.53)$ & $29(11.33)$ & \\
\hline Grade & & & & 0.368 \\
\hline Grade I (well differentiated) & $29(4.83)$ & $14(4.07)$ & $15(5.86)$ & \\
\hline Grade II (moderately differentiated) & $144(24.00)$ & $78(22.67)$ & $66(25.78)$ & \\
\hline Grade III(poorly differentiated) & $141(23.50)$ & $82(23.84)$ & $59(23.05)$ & \\
\hline Grade IV(undifferentiated) & $26(4.33)$ & $19(5.52)$ & $7(2.73)$ & \\
\hline Unknown & $260(43.33)$ & $151(43.90)$ & $109(42.58)$ & \\
\hline Histology & & & & 0.609 \\
\hline Squamous cell carcinoma & $299(49.83)$ & $171(49.71)$ & $128(50.00)$ & \\
\hline Adenoid cystic carcinoma & $107(17.83)$ & $64(18.60)$ & $43(16.80)$ & \\
\hline Small cell carcinoma & $51(8.50)$ & $25(7.27)$ & $26(10.16)$ & \\
\hline Others & $143(23.83)$ & $84(24.42)$ & $59(23.05)$ & \\
\hline Low-Grade Malignant Tumors ${ }^{d}$ & & & & 0.729 \\
\hline Yes & $133(22.17)$ & $78(22.67)$ & $55(21.48)$ & \\
\hline No & $467(77.83)$ & $266(77.33)$ & $201(78.52)$ & \\
\hline Surgery & & & & 0.744 \\
\hline Total resection & $39(6.50)$ & $25(7.27)$ & $14(5.47)$ & \\
\hline Subtotal resection & $230(38.33)$ & $134(38.95)$ & $96(37.50)$ & \\
\hline No cancer directed surgery & $323(53.83)$ & $180(52.33)$ & $143(55.86)$ & \\
\hline Unknown & $8(1.33)$ & $5(1.45)$ & $3(1.17)$ & \\
\hline Radiotherapy & & & & 0.657 \\
\hline Radiotherapy & $378(63.00)$ & $222(64.53)$ & $156(60.94)$ & \\
\hline No radiotherapy & $199(33.17)$ & $109(31.69)$ & $90(35.16)$ & \\
\hline Unknown & $23(3.83)$ & $13(3.78)$ & $10(3.91)$ & \\
\hline High School Education Rate & & & & 0.806 \\
\hline Lower $50 \%$ & $327(54.50)$ & $186(54.07)$ & $141(55.08)$ & \\
\hline Upper $50 \%$ & $273(45.50)$ & $158(45.93)$ & $115(44.92)$ & \\
\hline
\end{tabular}


Lower $50 \%$

Upper 50\%

Unemployed $^{\mathrm{e}}$

Lower 50\%

Upper $50 \%$

White Collar

Lower $50 \%$

Upper $50 \%$
$134(22.33)$

466 (77.77)

$309(51.50)$

$291(48.50)$

$184(30.67)$

$416(69.27)$
72 (20.93)

$62(24.22)$

$272(79.07)$

$194(75.78)$

0.890

$131(51.17)$

$125(48.83)$

77 (30.08)

$179(69.92)$

aData were presented as number (percentage) of patients.

${ }^{\mathrm{b}}$ Unmarried group included divorced cases, single (never married) cases, widowed cases and cases separated with spouse. ${ }^{c} p$ values were from the statistical analysis between married and unmarried patients.

${ }^{\mathrm{d}}$ Low-grade malignant tumors were defined as carcinoids, adenoid cystic carcinomas and mucoepidermoid carcinomas.

'Data generated from 2000 national census data. Lower 50\% indicated the patients live in counties below median level of national statistics. Upper 50\% indicated the patients live in counties above median level of national statistics.

SEER 1990-2010 $(n=600)^{\mathrm{a}}$.

[21] found that socioeconomic factors such as income influenced prognosis after lung cancer surgery. However, because of the rarity of primary tracheal cancer, prognostic factors, especially socioeconomic status, are unclear. Our study found that marital status is an independent prognostic factor for survival in primary tracheal cancer, with better OS and TCSS for married patients than unmarried patients. However, because this was a retrospective study, we could not establish a causal relationship between marital status and survival. Future prospective cohort studies are needed to determine any effect of marriage on survival in patients with tracheal cancer.

Results of subgroup analysis showed that marital status was an independent prognostic factor for TCSS in patients with NLGMTs but not in those with LGMTs. It is possible that patients with LGMTs had less need for social support, given the better prognosis associated with these tumors $[16,22,23]$. Although some studies have found

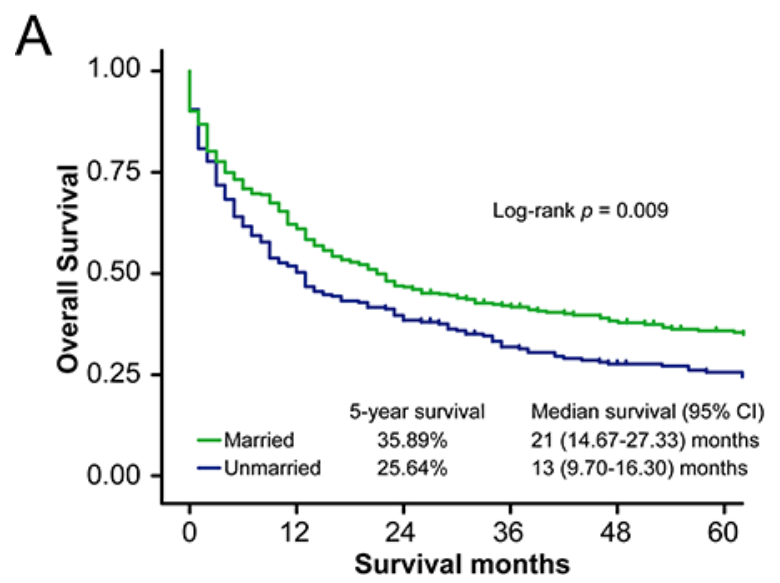

that marriage was more likely to be a protective factor in patients with advanced disease [20, 24, 25], our study failed to prove that marital status played a more important role in late stage patients than in early stage patients. Considering the relatively small size of each subgroup, future studies with larger sample size may be necessary to better test the relationship between marital status and survival according to tumor stage and histologic type.

Numerous studies have investigated the effect of marital status on cancer prognosis. One study evaluating survival among patients with cervical cancer reported an interaction between marital status with tumor stage and treatment [26]. A study on oral and laryngeal cancers suggested that married patients had earlier stage cancer at clinical presentation [27], possibly because a concerned spouse may encourage patients to seek medical help when symptoms are noticed. However, other studies showed no significant relationship between marital status

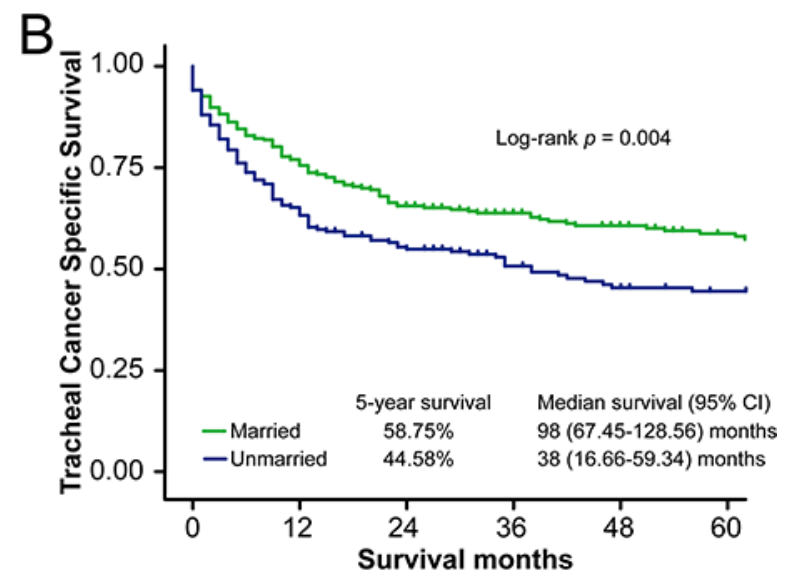

Figure 1: Survival curves in patients with tracheal cancer according to marital status, married vs. unmarried. (A) Overall survival (OS): $\chi^{2}=6.92, p=0.009$. (B) Tracheal cancer specific survival (TCSS): $\chi^{2}=8.11, p=0.004$. 
Table 2: Univariate and multivariate analysis for overall survival (OS) in tracheal cancer patients

\begin{tabular}{|c|c|c|c|c|c|c|}
\hline \multirow[t]{2}{*}{ Variables } & \multirow{2}{*}{ 5-year OS } & \multicolumn{2}{|c|}{ Univariate analysis } & \multicolumn{3}{|c|}{ Multivariate analysis } \\
\hline & & $\log \operatorname{rank} \chi^{2}$ & $P$ value & HR & $95 \% \mathrm{CI}$ & $P$ value \\
\hline Sex & & 2.82 & 0.093 & & & \\
\hline Female & $33.73 \%$ & & & Reference & & \\
\hline Male & $29.77 \%$ & & & 0.82 & $0.67-1.01$ & 0.061 \\
\hline Age at diagnosis & & 107.73 & $<0.001$ & & & \\
\hline$<65$ & $49.21 \%$ & & & Reference & & \\
\hline$\geq 65$ & $14.66 \%$ & & & 2.00 & $1.62-2.46$ & $<0.001$ \\
\hline Race & & 8.88 & 0.012 & & & \\
\hline White & $28.18 \%$ & & & Reference & & \\
\hline Black & $37.96 \%$ & & & 0.90 & $0.67-1.20$ & 0.467 \\
\hline Other & $53.92 \%$ & & & 0.90 & $0.60-1.34$ & 0.600 \\
\hline Histology & & 133.81 & $<0.001$ & & & \\
\hline Squamous cell carcinoma & $18.45 \%$ & & & Reference & & \\
\hline Adenoid cystic carcinoma & $75.12 \%$ & & & 0.82 & $0.38-1.75$ & 0.601 \\
\hline Small cell carcinoma & $0.00 \%$ & & & 1.22 & $0.86-1.73$ & 0.264 \\
\hline Others & $36.98 \%$ & & & 0.66 & $0.50-0.86$ & 0.002 \\
\hline Low-Grade Malignant Tumors & & 109.38 & $<0.001$ & & & \\
\hline Yes & $72.88 \%$ & & & Reference & & \\
\hline No & $19.74 \%$ & & & 2.27 & $1.15-4.47$ & 0.018 \\
\hline Grade & & 23.16 & $<0.001$ & & & \\
\hline Grade I (well differentiated) & $57.39 \%$ & & & Reference & & \\
\hline Grade II (moderately differentiated) & $33.26 \%$ & & & 1.27 & $0.71-2.27$ & 0.416 \\
\hline Grade III (poorly differentiated) & $16.74 \%$ & & & 1.73 & $0.97-3.11$ & 0.065 \\
\hline Grade IV (undifferentiated) & $17.31 \%$ & & & 1.59 & $0.77-3.26$ & 0.209 \\
\hline Unknown & $37.64 \%$ & & & 1.35 & $0.77-2.36$ & 0.294 \\
\hline Disease Extension & & 99.00 & $<0.001$ & & & \\
\hline Localized & $45.49 \%$ & & & Reference & & \\
\hline Regional & $31.24 \%$ & & & 1.65 & $1.29-2.10$ & $<0.001$ \\
\hline Distant & $11.01 \%$ & & & 2.75 & $2.06-3.69$ & $<0.001$ \\
\hline Unknown & $18.29 \%$ & & & 1.50 & $1.10-2.04$ & 0.009 \\
\hline Surgery & & 167.92 & $<0.001$ & & & \\
\hline Surgery-total resection & $61.09 \%$ & & & Reference & & \\
\hline Surgery-subtotal resection & $52.26 \%$ & & & 1.80 & $1.06-3.05$ & 0.029 \\
\hline No cancer directed surgery & $13.33 \%$ & & & 3.75 & $2.20-6.39$ & $<0.001$ \\
\hline Unknown & $25.00 \%$ & & & 2.72 & $1.04-7.11$ & 0.041 \\
\hline Radiotherapy & & 7.58 & 0.023 & & & \\
\hline Radiotherapy & $33.39 \%$ & & & Reference & & \\
\hline No radiotherapy & $28.38 \%$ & & & 2.06 & $1.62-2.61$ & $<0.001$ \\
\hline Unknown & $27.05 \%$ & & & 1.69 & $0.95-3.03$ & 0.076 \\
\hline
\end{tabular}


Marital Status

Unmarried

$25.64 \%$

Married

High School Education Rate

Lower 50\%

$35.89 \%$

Upper 50\%

Median Household Income

Lower 50\%

Upper 50\%

Unemployed

Lower 50\%

Upper 50\%

White Collar

Lower $50 \%$

Upper 50\%

SEER 1990-2010 $(n=600)$.

and tumor stage at presentation [20, 28]. In our study, we found no significant difference in disease extension or treatment selection between married and unmarried patients (Table 1). Thus, other explanations are needed to understand the relationship between marital status and prognosis in tracheal cancer.

Emotional state could be one reason. In cancer patients, clinical-level psychological distress was found to be more common in unmarried patients than in married patients, and psychological distress was negatively correlated with social support among married patients [29]. Cancer patients often experience high levels of anxiety and depression $[14,30]$, and this can affect the immune system through glucocorticoid resistance and decreased interleukin 6 level [31]. In addition, long-term stress can alter the type $1 /$ type 2 cytokine balance, leading to low-grade chronic inflammation and immune cell dysfunction [32], which are related to tumor metastasis [33-35]. In addition, married status generally reflects a better financial situation, which has been reported to improve prognosis [36]. Furthermore, unmarried patients may have additional health care expenditures, as spouses are the major source of outpatient/informal care [37]. Previous studies have found that married patients are more likely to receive better quality clinical care, choose better medical centers, be more compliant with medical recommendations, receive more aggressive treatments, and recover better from surgery, all of which contribute to a better prognosis [38-40].

The effects of other socioeconomic factors have also been discussed in numerous studies. Although most studies suggested that personal income is related to cancer survival [41, 42], the impact of the regional economic environment (e.g., county-level median household income)
$6.92 \quad 0.009$

$\begin{array}{ccc}\text { Reference } & & \\ 0.78 & 0.64-0.95 & 0.015\end{array}$

$\begin{array}{ll}0.74 & 0.389\end{array}$

Reference

$0.87 \quad 0.65-1.16 \quad 0.332$

$0.66 \quad 0.417$

Reference

$1.21 \quad 0.92-1.58 \quad 0.166$

$1.19 \quad 0.275$

Reference

$0.90 \quad 0.70-1.17 \quad 0.445$

$\begin{array}{ll}3.57 & 0.059\end{array}$

Reference

$\begin{array}{lll}0.85 & 0.66-1.10 \quad 0.206\end{array}$ remains controversial. Higher neighborhood income level has been associated with higher survival rates, which can be partially explained by differences in disease stage at presentation, first-line treatment, and comorbidities $[41,43,44]$. However, other studies reported no significant correlation between county-level income and survival [45] or an association only for patients with early stage disease [46]. Higher education level at the community level has also been identified as having a positive influence on survival $[42,47]$; however, our analysis did not show that county-level economic status or education was significant independent prognostic factors. Finally, several studies found that race influenced prognosis for certain types of cancer (e.g., lung, liver, breast, and prostate) [48], whereas other studies found that the effect was minimal after adjusting for other socioeconomic factors [49], which is consistent with our results.

SEER provided us the opportunity to have a relatively large sample size for this rare disease. However, our study still has certain limitations. First, presently SEER does not differentiate between cohabitation (quasimarriage) and single status; thus, patients who live with their partners may be categorized as unmarried in the SEER database. According to the United States census data, unmarried partners comprise $5.19 \%$ of all households [50]. These patients may have better outcomes than unmarried patients who do not live with their partners, potentially biasing our results towards the null. This factor should be taken into consideration, and more data regarding cohabitation and quasi-marriage status is needed in future studies. Second, the database did not provide information related to sexual minority status (lesbian, gay, bisexual, or transgender). Several studies have suggested that these patients may have different types of social support and 
Table 3: Univariate and multivariate analysis for tracheal cancer specific survival (TCSS) in tracheal cancer patients

\begin{tabular}{|c|c|c|c|c|c|c|}
\hline \multirow[t]{2}{*}{ Variables } & \multirow{2}{*}{ 5-year TCSS } & \multicolumn{2}{|c|}{ Univariate analysis } & \multicolumn{2}{|c|}{ Multivariate analysis } & \multirow[b]{2}{*}{$P$ value } \\
\hline & & $\log \operatorname{rank} \chi^{2}$ & $P$ value & HR & $95 \%$ CI & \\
\hline Sex & & 2.45 & 0.118 & & & \\
\hline Female & $55.69 \%$ & & & Reference & & \\
\hline Male & $50.38 \%$ & & & 0.83 & $0.63-1.08$ & 0.161 \\
\hline Age at diagnosis & & 23.16 & $<0.001$ & & & \\
\hline$<65$ & $61.91 \%$ & & & Reference & & \\
\hline$\geq 65$ & $41.27 \%$ & & & 1.44 & $1.10-1.89$ & 0.008 \\
\hline Race & & 7.62 & 0.022 & & & \\
\hline White & $48.88 \%$ & & & Reference & & \\
\hline Black & $66.47 \%$ & & & 0.74 & $0.49-1.13$ & 0.168 \\
\hline Other & $67.87 \%$ & & & 1.11 & $0.66-1.86$ & 0.696 \\
\hline Histology & & 88.86 & $<0.001$ & & & \\
\hline Squamous cell carcinoma & $40.85 \%$ & & & Reference & & \\
\hline Adenoid cystic carcinoma & $84.44 \%$ & & & 0.84 & $0.30-2.39$ & 0.750 \\
\hline Small cell carcinoma & $0.00 \%$ & & & 1.42 & $0.92-2.19$ & 0.109 \\
\hline Others & $60.25 \%$ & & & 0.67 & $0.46-0.97$ & 0.034 \\
\hline Low-Grade Malignant Tumors & & 53.23 & $<0.001$ & & & \\
\hline Yes & $83.17 \%$ & & & Reference & & \\
\hline No & $41.53 \%$ & & & 2.25 & $0.87-5.84$ & 0.094 \\
\hline Grade & & 13.77 & 0.008 & & & \\
\hline Grade I (well differentiated) & $78.24 \%$ & & & Reference & & \\
\hline Grade II (moderately differentiated) & $58.88 \%$ & & & 1.12 & $0.52-2.43$ & 0.773 \\
\hline Grade III (poorly differentiated) & $35.44 \%$ & & & 1.50 & $0.69-3.23$ & 0.306 \\
\hline Grade IV (undifferentiated) & $32.34 \%$ & & & 1.75 & $0.70-4.41$ & 0.234 \\
\hline Unknown & $56.89 \%$ & & & 1.47 & $0.70-3.08$ & 0.305 \\
\hline Disease Extension & & 116.12 & $<0.001$ & & & \\
\hline Localized & $74.72 \%$ & & & Reference & & \\
\hline Regional & $44.97 \%$ & & & 2.76 & $1.94-3.93$ & $<0.001$ \\
\hline Distant & $21.50 \%$ & & & 4.80 & $3.23-7.14$ & $<0.001$ \\
\hline Unknown & $46.50 \%$ & & & 2.20 & $1.41-3.43$ & 0.001 \\
\hline Surgery & & 94.28 & $<0.001$ & & & \\
\hline Surgery-total resection & $73.68 \%$ & & & Reference & & \\
\hline Surgery-subtotal resection & $71.17 \%$ & & & 1.69 & $0.88-3.27$ & 0.117 \\
\hline No cancer directed surgery & $33.50 \%$ & & & 3.27 & $1.69-6.34$ & $<0.001$ \\
\hline Unknown & $37.50 \%$ & & & 3.49 & $1.15-10.59$ & 0.028 \\
\hline Radiotherapy & & 1.45 & 0.484 & & & \\
\hline Radiotherapy & $53.36 \%$ & & & Reference & & \\
\hline No radiotherapy & $52.24 \%$ & & & 1.80 & $1.31-2.47$ & $<0.001$ \\
\hline Unknown & $56.79 \%$ & & & 1.08 & $0.47-2.49$ & 0.854 \\
\hline
\end{tabular}




\begin{tabular}{|c|c|c|c|c|c|c|}
\hline Marital Status & & 8.11 & 0.004 & & & \\
\hline Unmarried & $44.58 \%$ & & & Reference & & \\
\hline Married & $58.75 \%$ & & & 0.70 & $0.54-0.91$ & 0.008 \\
\hline High School Education Rate & & 0.96 & 0.327 & & & \\
\hline Lower $50 \%$ & $54.80 \%$ & & & Reference & & \\
\hline Upper $50 \%$ & $50.43 \%$ & & & 1.08 & $0.74-1.59$ & 0.679 \\
\hline Median Household Income & & 5.10 & 0.023 & & & \\
\hline Lower $50 \%$ & $42.86 \%$ & & & Reference & & \\
\hline Upper $50 \%$ & $55.81 \%$ & & & 0.97 & $0.69-1.36$ & 0.858 \\
\hline Unemployed & & 0.03 & 0.863 & & & \\
\hline Lower $50 \%$ & $53.26 \%$ & & & Reference & & \\
\hline Upper 50\% & $52.19 \%$ & & & 1.25 & $0.88-1.76$ & 0.210 \\
\hline White Collar & & 2.50 & 0.114 & & & \\
\hline Lower $50 \%$ & $46.20 \%$ & & & Reference & & \\
\hline Upper 50\% & $55.62 \%$ & & & 1.02 & $0.72-1.43$ & 0.933 \\
\hline
\end{tabular}

SEER 1990-2010 $(n=600)$.

prognostic factors [51-53]. Thus, future studies on the relationship between marital status and cancer prognosis should take sexual orientation into account. Third, the database did not provide details about the quality of the marriage (e.g., satisfaction with the relationship, sexual activity), which limits the ability to analyze the impact of marriage on prognosis in tracheal cancer. In addition, the study did not analyze changes in marital status, length of the marriage, duration of being single, lifestyle risk factors, or individual-level socioeconomic factors. As the final comment, several important clinical or treatment factors that may affect survival is also not registered in SEER, including details of surgery or treatment of chemotherapy and quality of treatment at various institutions. To verify our results, further studies with detailed data at both the county and individual levels are warranted.

In conclusion, our study based on the SEER database shows that marital status is an independent prognostic factor for survival in patients with tracheal cancer. To improve prognosis, additional social support should be considered for unmarried patients, especially those with NLGMTs. The impact of other individuallevel socioeconomic factors on survival requires further study.
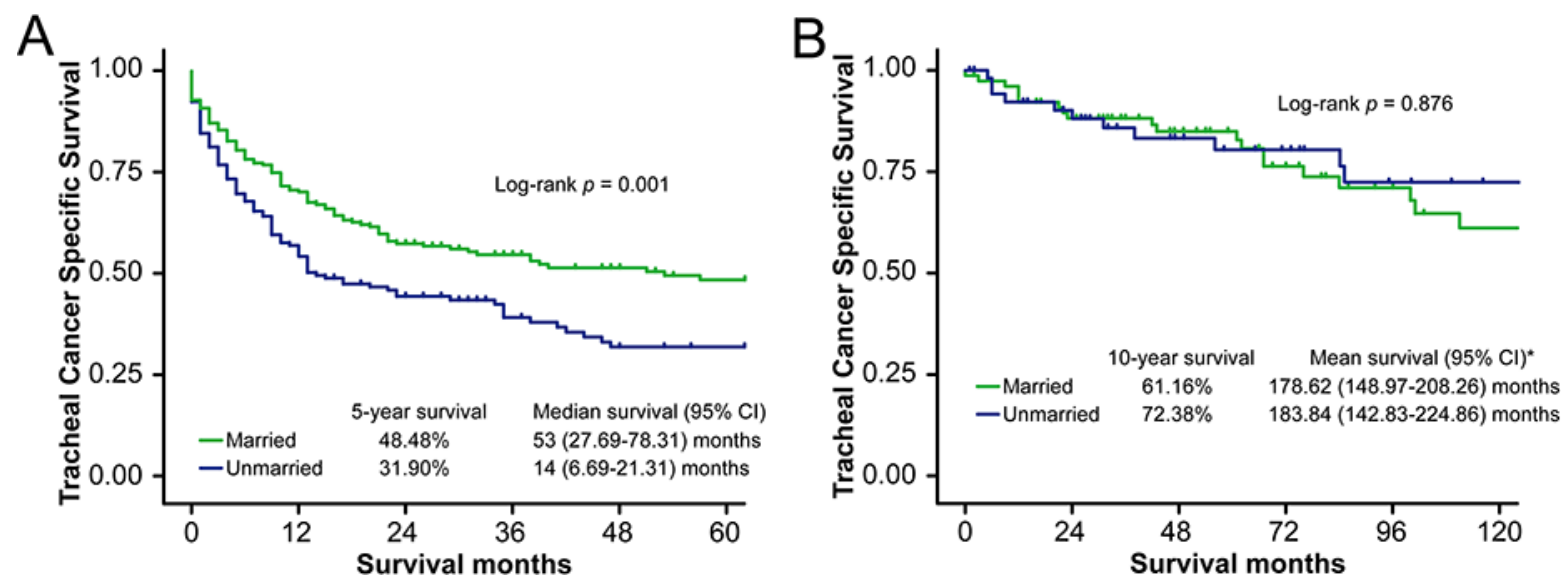

Figure 2: Survival curves in NLGMT and LGMT subgroup patients, married vs. unmarried. (A) NLGMT subgroup, tracheal cancer specific survival (TCSS): $\chi^{2}=10.60, p=0.001$. (B) LGMT subgroup, tracheal cancer specific survival (TCSS): $\chi^{2}=0.02$, $p=0.876$. * No "median survival" calculated in LGMT subgroup because event happened in less than $50 \%$ patients at the end of follow-up. 


\section{MATERIALS AND METHODS}

\section{Data sources}

All primary data were obtained by using SEER*Stat software version 8.3.2 and the SEER database released in April 2015. County-level socioeconomic information for the year 2000 was obtained from US Census 2000 files, made available by the US Census Bureau and linked to the SEER database.

\section{Inclusion and exclusion criteria}

Information about patients with malignancies of the "trachea, mediastinum, and other respiratory organs" from January 1990 to December 2010 was extracted from the SEER database. Patients with histologically confirmed primary tracheal cancer (International Classification of Diseases for Oncology, Third Edition [ICD-O-3], code C33.9) were considered for analysis. Exclusion criteria were incomplete follow-up information, unknown survival time or survival time of 0 days, age $<18$ years, unknown race, and unknown marital status (Supplementary Figure S1).

\section{Study variables}

Clinically related information extracted from the SEER database included sex, age, race, primary tumor site, histologic type, tumor grade, disease extension, surgical record, and radiotherapy. Patients were divided into two groups according to age ( $<65$ years vs. $\geq 65$ years). Race was classified as white, black, or other. Histologic type was further classified as squamous cell carcinoma, adenoid cystic carcinoma, small cell carcinoma, or other. Histologic type was further classified as LGMT vs. NLGMT, as previously described [16], with carcinoids, adenoid cystic carcinomas, and mucoepidermoid carcinomas defined as LGMTs, and all other histologic types defined as NLGMTs. Disease extension was categorized using the Collaborative Stage classification criteria, with "localized" indicating situ lesions or lesions confined to the organ of origin, "regional" indicating invasion into surrounding organs/adjacent tissues or regional lymph node metastasis, and "distant" indicating distant metastasis. The surgical record was categorized as complete, partial, none, or unknown, and procedures were listed as "radical surgery" or "total surgical removal of primary site"; "local tumor destruction" or "local tumor excision"; "simple/partial surgical removal of primary site" or "debulking"; "none"; or "unknown" in the SEER database.

Marital status was categorized as married or unmarried (including never married single, divorced, separated, and widowed). Socioeconomic factors included the following county attributes: high school education rate, median household income, unemployment rate, and proportion of white-collar workers in the population. All county attributes variables were divided into two groups by the median number.

\section{Outcomes}

The primary outcomes were OS and TCSS. OS was defined as the time from diagnosis to date of death from any cause. Patients who were alive on the date of last contact or at the follow-up cut-off date were censored. TCSS was defined as the time from diagnosis to date of death due to tracheal cancer. Death caused by tracheal cancer was considered an event. Patients who died from other causes or were still alive at the end of the study were censored. The follow-up cut-off date was December 31, 2012, according to the SEER database instructions.

\section{Statistical analyses}

Demographic, clinical, and socioeconomic characteristics were reported as means and standard deviations for continuous variables and percentages for categorical variables. Differences in baseline characteristics were compared by Pearson chi-squared test for categorical variables and $t$-test for continuous variables. OS and TCSS were calculated by the KaplanMeier method and log-rank tests were conducted to compare differences between subgroups of each variable. Multivariate Cox proportional hazard models were used to determine risk factors that affect survivorship. All $P$ values were two-sided, and a value less than 0.05 were considered significant. All data were analyzed by SPSS version 20 (Statistics Package for Social Science, Chicago, IL).

\section{ACKNOWLEDGMENTS}

The authors acknowledge the efforts of the Surveillance, Epidemiology, and End Results (SEER) Program tumor registries in providing high quality open resources for researchers.

$\mathrm{Mu} \mathrm{Li}$, Chenyang Dai and Chang Chen designed the study and wrote the manuscript. Tao Chen, Rui Mao and Long Wang collected the relevant papers and data. $\mathrm{Mu} \mathrm{Li}$ and Yuning Wang analyzed the data. Dong Xie and Ping Yang contributed in study design, statistical analysis and manuscript editing. All authors reviewed the manuscript.

\section{CONFLICTS OF INTEREST}

All of the authors have no conflicts of interested to declare.

\section{GRANT SUPPORT}

This study was supported by supported by the grants from the National Natural Science Foundation of China (No.81570014) and the projects from Science 
and Technology Commission of Shanghai Municipality (No.15JC1490900 and No.14411962600), Shanghai Pujiang Program (15PJD034), and Health and Family Planning Commission of Shanghai Municipality (No.2013ZYJB0003).

\section{REFERENCES}

1. Lawrence DA, Branson B, Oliva I, Rubinowitz A. The wonderful world of the windpipe: a review of central airway anatomy and pathology. Canadian Association of Radiologists journal $=$ Journal l'Association canadienne des radiologistes. 2015; 66:30-43.

2. Urdaneta AI, Yu JB, Wilson LD. Population based cancer registry analysis of primary tracheal carcinoma. Am J Clin Oncol. 2011; 34:32-37.

3. Gaissert HA, Mark EJ. Tracheobronchial gland tumors. Cancer Control. 2006; 13:286-294.

4. Hetnal M, Kielaszek-Cmiel A, Wolanin M, Korzeniowski S, Brandys P, Malecki K, Sas-Korczynska B, Chlosta M, Kokoszka A. Tracheal cancer: Role of radiation therapy. Rep Pract Oncol Radiother. 2010; 15:113-118.

5. Yang H, Yao F, Tantai J, Zhao Y, Tan Q, Zhao H. Resected Tracheal Adenoid Cystic Carcinoma: Improvements in Outcome at a Single Institution. Ann Thorac Surg. 2016; 101:294-300.

6. Yasumatsu R, Fukushima J, Nakashima T, Kadota H, Segawa Y, Tamae A, Kato M, Komune S. Surgical management of malignant tumors of the trachea: report of two cases and review of literature. Case Rep Oncol. 2012; 5:302-307.

7. Abbate G, Lancella A, Contini R, Scotti A. A primary squamous cell carcinoma of the trachea: case report and review of the literature. Acta Otorhinolaryngol Ital. 2010; 30:209.

8. Engel GL. The need for a new medical model: a challenge for biomedicine. Science. 1977; 196:129-136.

9. Adler RH. Engel's biopsychosocial model is still relevant today. J Psychosom Res. 2009; 67:607-611.

10. Sherani K, Vakil A, Dodhia C, Fein A. Malignant tracheal tumors: a review of current diagnostic and management strategies. Curr Opin Pulm Med. 2015; 21:322-326.

11. Aizer AA, Chen MH, McCarthy EP, Mendu ML, Koo S, Wilhite TJ, Graham PL, Choueiri TK, Hoffman KE, Martin NE, Hu JC, Nguyen PL. Marital status and survival in patients with cancer. Journal of clinical oncology. 2013; 31:3869-3876.

12. Osborne C, Ostir GV, Du X, Peek MK, Goodwin JS. The influence of marital status on the stage at diagnosis, treatment, and survival of older women with breast cancer. Breast Cancer Res Treat. 2005; 93:41-47.

13. Wang XD, Qian JJ, Bai DS, Li ZN, Jiang GQ, Yao J. Marital status independently predicts pancreatic cancer survival in patients treated with surgical resection: an analysis of the SEER database. Oncotarget. 2016; 7:24880-7. doi: 10.18632/oncotarget.8467.
14. Nipp RD, El-Jawahri A, Fishbein JN, Eusebio J, Stagl JM, Gallagher ER, Park ER, Jackson VA, Pirl WF, Greer JA, Temel JS. The relationship between coping strategies, quality of life, and mood in patients with incurable cancer. Cancer. 2016.

15. Byers TE, Wolf HJ, Bauer KR, Bolick-Aldrich $\mathrm{S}$, Chen VW, Finch JL, Fulton JP, Schymura MJ, Shen T, Van Heest S, Yin X, Patterns of Care Study G. The impact of socioeconomic status on survival after cancer in the United States. 2008; 113:582-591.

16. Zheng H, Xie HK, Li C, Bao F, Ding JA, Jiang GN, Zhang RX, Chen C. Radical mediastinal nodal removal improves disease-free survival for pulmonary low-grade malignant tumors. Lung cancer. 2012; 75:342-347.

17. Van Keer RL, Deschepper R, Francke AL, Huyghens L, Bilsen J. Conflicts between healthcare professionals and families of a multi-ethnic patient population during critical care: an ethnographic study. Crit Care. 2015; 19:441.

18. Alonso Y. The biopsychosocial model in medical research: the evolution of the health concept over the last two decades. Patient Educ Couns. 2004; 53:239-244.

19. Levine RS, Kilbourne BA, Rust GS, Langston MA, Husaini BA, Gittner LS, Sanderson M, Hennekens CH. Social determinants and the classification of disease: descriptive epidemiology of selected socially mediated disease constellations. PLoS One. 2014; 9:e110271.

20. Zhang J, Gan L, Wu Z, Yan S, Liu X, Guo W. The influence of marital status on the stage at diagnosis, treatment, and survival of adult patients with gastric cancer: a population-based study. Oncotarget. 2016. doi: 10.18632/ oncotarget.7399.

21. LaPar DJ, Bhamidipati CM, Harris DA, Kozower BD, Jones DR, Kron IL, Ailawadi G, Lau CL. Gender, race, and socioeconomic status affects outcomes after lung cancer resections in the United States. Ann Thorac Surg. 2011; 92:434-439.

22. Honings J, van Dijck JA, Verhagen AF, van der Heijden HF, Marres HA. Incidence and treatment of tracheal cancer: a nationwide study in the Netherlands. Annals of surgical oncology. 2007; 14:968-976.

23. Macchiarini P. Primary tracheal tumours. The Lancet Oncology. 2006; 7:83-91.

24. Zhou R, Yan S, Li J. Influence of marital status on the survival of patients with gastric cancer. Journal of gastroenterology and hepatology. 2016; 31:768-775.

25. Wang XD, Qian JJ, Bai DS, Li ZN, Jiang GQ, Yao J. Marital status independently predicts pancreatic cancer survival in patients treated with surgical resection: an analysis of the SEER database. Oncotarget. 2016; 7:24880-24887. doi: 10.18632/oncotarget.8467.

26. Patel MK, Patel DA, Lu M, Elshaikh MA, Munkarah A, Movsas B. Impact of marital status on survival among women with invasive cervical cancer: analysis of population-based surveillance, epidemiology, and end results data. J Low Genit Tract Dis. 2010; 14:329-338. 
27. Inverso G, Mahal BA, Aizer AA, Donoff RB, Chau NG, Haddad RI. Marital status and head and neck cancer outcomes. Cancer. 2015; 121:1273-1278.

28. Mwaka AD, Garimoi CO, Were EM, Roland M, Wabinga H, Lyratzopoulos G. Social, demographic and healthcare factors associated with stage at diagnosis of cervical cancer: cross-sectional study in a tertiary hospital in Northern Uganda. BMJ Open. 2016; 6:e007690.

29. Goldzweig G, Andritsch E, Hubert A, Brenner B, Walach N, Perry S, Baider L. Psychological distress among male patients and male spouses: what do oncologists need to know? Ann Oncol. 2010; 21:877-883.

30. Nipp RD, El-Jawahri A, Fishbein JN, Gallagher ER, Stagl JM, Park ER, Jackson VA, Pirl WF, Greer JA, Temel JS. Factors associated with depression and anxiety symptoms in family caregivers of patients with incurable cancer. Ann Oncol. 2016.

31. Uchino BN. Social support and health: a review of physiological processes potentially underlying links to disease outcomes. J Behav Med. 2006; 29:377-387.

32. Dhabhar FS. Effects of stress on immune function: the good, the bad, and the beautiful. Immunol Res. 2014; 58:193-210.

33. Wculek SK, Malanchi I. Neutrophils support lung colonization of metastasis-initiating breast cancer cells. Nature. 2015; 528:413-417.

34. Xu AM, Huang L, Zhu L, Wei ZJ. Significance of peripheral neutrophil-lymphocyte ratio among gastric cancer patients and construction of a treatment-predictive model: a study based on 1131 cases. Am J Cancer Res. 2014; 4:189-195.

35. Williams KA, Labidi-Galy SI, Terry KL, Vitonis AF, Welch WR, Goodman A, Cramer DW. Prognostic significance and predictors of the neutrophil-to-lymphocyte ratio in ovarian cancer. Gynecol Oncol. 2014; 132:542-550.

36. Woods LM, Rachet B, Coleman MP. Origins of socioeconomic inequalities in cancer survival: a review. Ann Oncol. 2006; 17:5-19.

37. Rolden HJ, van Bodegom D, Westendorp RG. Changes in health care expenditure after the loss of a spouse: data on 6,487 older widows and widowers in the Netherlands. PLoS One. 2014; 9:e115478.

38. Simeonova E. Marriage, bereavement and mortality: the role of health care utilization. J Health Econ. 2013; 32:33-50.

39. Iwashyna TJ, Christakis NA. Marriage, widowhood, and health-care use. Soc Sci Med. 2003; 57:2137-2147.

40. Neuman MD, Werner RM. Marital Status and Postoperative Functional Recovery. JAMA Surg. 2016; 151:194-196.

41. Dalton SO, Steding-Jessen M, Jakobsen E, Mellemgaard A, Osterlind K, Schuz J, Johansen C. Socioeconomic position and survival after lung cancer: Influence of stage, treatment and comorbidity among Danish patients with lung cancer diagnosed in 2004-2010. Acta Oncol. 2015; 54:797-804.
42. Lagergren J, Andersson G, Talback M, Drefahl S, Bihagen E, Harkonen J, Feychting M, Ljung R. Marital status, education, and income in relation to the risk of esophageal and gastric cancer by histological type and site. Cancer. 2016; 122:207-212.

43. Boyd C, Zhang-Salomons JY, Groome PA, Mackillop WJ. Associations between community income and cancer survival in Ontario, Canada, and the United States. J Clin Oncol. 1999; 17:2244-2255.

44. Shugarman LR, Sorbero ME, Tian H, Jain AK, Ashwood JS. An exploration of urban and rural differences in lung cancer survival among medicare beneficiaries. Am J Public Health. 2008; 98:1280-1287.

45. Tammemagi CM, Neslund-Dudas C, Simoff M, Kvale P. In lung cancer patients, age, race-ethnicity, gender and smoking predict adverse comorbidity, which in turn predicts treatment and survival. J Clin Epidemiol. 2004; 57:597-609.

46. Ou SH, Zell JA, Ziogas A, Anton-Culver H. Low socioeconomic status is a poor prognostic factor for survival in stage I nonsmall cell lung cancer and is independent of surgical treatment, race, and marital status. Cancer. 2008; 112:2011-2020.

47. Erhunmwunsee L, Joshi MB, Conlon DH, Harpole DH, Jr. Neighborhood-level socioeconomic determinants impact outcomes in nonsmall cell lung cancer patients in the Southeastern United States. Cancer. 2012; 118:5117-5123.

48. Kish JK, Yu M, Percy-Laurry A, Altekruse SF. Racial and ethnic disparities in cancer survival by neighborhood socioeconomic status in Surveillance, Epidemiology, and End Results (SEER) Registries. J Natl Cancer Inst Monogr. 2014; 2014:236-243.

49. Aldrich MC, Grogan EL, Munro HM, Signorello LB, Blot WJ. Stage-adjusted lung cancer survival does not differ between low-income Blacks and Whites. J Thorac Oncol. $2013 ; 8: 1248-1254$.

50. Lofquist DLT, O'Connell M, Feliz, S. Household and Families: 2010. United States Census Bureau). 2012.

51. Boehmer U, Glickman M, Winter M, Clark MA. Breast cancer survivors of different sexual orientations: which factors explain survivors' quality of life and adjustment? Annals of oncology. 2013; 24:1622-1630.

52. Paul LB, Pitagora D, Brown B, Tworecke A, Rubin L. Support needs and resources of sexual minority women with breast cancer. Psycho-oncology. 2014; 23:578-584.

53. Rosario M, Corliss HL, Everett BG, Reisner SL, Austin SB, Buchting FO, Birkett M. Sexual orientation disparities in cancer-related risk behaviors of tobacco, alcohol, sexual behaviors, and diet and physical activity: pooled Youth Risk Behavior Surveys. American journal of public health. 2014; 104:245-254. 